\title{
A chest physician's guide to mechanisms of sinonasal disease
}

\author{
V Hox ${ }^{1,2}$ T Maes, $^{3}$ W Huvenne, ${ }^{4}$ C Van Drunen, ${ }^{5}$ J A Vanoirbeek $^{6}{ }^{6} \mathrm{G} \mathrm{Joos},{ }^{3}$ \\ C Bachert, ${ }^{4}$ W Fokkens, ${ }^{5} \mathrm{~J}$ L Ceuppens, ${ }^{2}$ B Nemery, ${ }^{6}$ P W Hellings ${ }^{1,2}$
}

- Additional material is published online only. To view please visit the journal online (http://dx.doi.org/10.1136/ thoraxjnl-2014-205520).

${ }^{1}$ Clinical Division of Otorhinolaryngology-Head and Neck Surgery, University Hospitals Leuven, Leuven, Belgium

${ }^{2}$ Laboratory of Clinical Immunology, Department of Microbiology and Immunology, KU Leuven, Leuven, Belgium ${ }^{3}$ Laboratory for Translational Research in Obstructive Pulmonary Diseases, Department of Respiratory Medicine, Ghent University Hospital, Belgium

${ }^{4}$ Upper Airways Research Laboratory, Department of Otorhinolaryngology-Head and Neck Surgery, University of Ghent, Belgium ${ }^{5}$ Department of

Otorhinolaryngology, Academic Medical Center, Amsterdam, The Netherlands

${ }^{6}$ Research Unit of Lung Toxicology, Department of Public Health, K U Leuven, Leuven, Belgium

\section{Correspondence to}

Dr Valerie Hox, Clinical Division of

Otorhinolaryngology-Head and Neck Surgery, University Hospitals Leuven,

Kapucijnenvoer 33, 3000

Leuven, Belgium; valeriehox@ gmail.com

Received 2 April 2014 Revised 25 November 2014 Accepted 5 December 2014 Published Online First 6 January 2015

\section{CrossMark}

To cite: Hox V, Maes T, Huvenne $W$, et al. Thorax 2015;70:353-358.

\section{ABSTRACT}

The upper and lower airways are closely linked from an anatomical, histological and immunological point of view, with inflammation in one part of the airways influencing the other part. Despite the concept of global airway disease, the upper airways tend to be overlooked by respiratory physicians. We provide a clinical overview of the most important and recent insights in rhinitis and rhinosinusitis in relation to lower airway disease. We focus on the various exogenous and endogenous factors that play a role in the development and aggravation of chronic upper airway inflammation. In addition to the classical inhaled allergens or microorganisms with welldefined pathophysiological mechanisms in upper airway disease, environmental substances such as cigarette smoke, diesel exhaust particles and occupational agents affecting lower airway homeostasis have recently gained attention in upper airway research. We are only at the beginning of understanding the complex interplay between exogenous and endogenous factors like genetic, immunological and hormonal influences on chronic upper airway inflammation. From a clinical perspective, the involvement of upper and lower airway disease in one patient can only be fully appreciated by doctors capable of understanding the interplay between upper and lower airway inflammation.

\section{INTRODUCTION}

Due to its position at the entry of the airways, the nasal mucosa is continuously exposed to inhaled agents from the environment. In order to prevent continuous inflammation induced by exogenous stimuli, the nasal epithelium is armed with a variety of mechanisms contributing to mucosal homeostasis including nasal epithelial cells with tight junction molecules, mucus production and ciliary function. The environment in which we live and work contains pathogens, allergens and irritants that can lead to inflammation of the upper airway mucosa. However, endogenous factors also play a role in the manifestation of chronic upper airway inflammation.

The most common upper airway disease is rhinitis, which is defined as a symptomatic inflammation of the nasal mucosa. ${ }^{1}$ Rhinosinusitis is defined as inflammation of the sinonasal mucosa which can present with or without nasal polyps. ${ }^{2}$ Depending on the duration of symptoms, we distinguish acute rhinosinusitis (ARS; <12 weeks) and chronic rhinosinusitis (CRS; $>12$ weeks) (see additional information in online supplement).

The close link between upper and lower airway inflammation is well known in the context of 'global airway disease' referring to the common coexistence of upper and lower airway symptoms, especially in patients with asthma and chronic obstructive pulmonary disease (COPD).

This review (and the synopsis in table 1) focuses on both endogenous predisposing factors and exogenous triggers that may contribute to chronic upper airway disease and that can also impact lower airway disease.

\section{ENDOGENOUS FACTORS ASSOCIATED WITH UPPER AIRWAY DISEASE \\ Genetic factors}

Atopy is a strong hereditary predisposing factor for allergic rhinitis and allergic asthma. Additionally, polymorphisms in the interleukin 13 (IL-13) gene, one of the genes that has been most consistently associated with asthma, were also linked to allergic rhinitis to moulds in a large Korean study. ${ }^{3}$ Patients with mutations in the transforming growth factor $\beta$ (TGF- $\beta$ ) receptor gene are strongly predisposed to develop both allergic rhinitis and asthma. ${ }^{4}$ Polymorphisms in the Toll-like receptor (TLR) 7 and 8 gene areas were also associated with allergic rhinitis in Swedish and Chinese populations. ${ }^{5}$ Moreover, the same Swedish group identified 10 genes that were linked to non-allergic rhinitis. ${ }^{6}$ Among these genes, Cfos (encoding a transcription factor activated by airway exposure to toxins and irritants) and $C d c 42$ (encoding a GTPase implicated in the cell cycle) seem to be the most promising genes because they control and modulate genes or pathways that can be implicated in airway disease.

So far, 53 single nucleotide polymorphisms (SNPs) have been associated with CRS, with specific polymorphisms in genes involved in leukotriene and prostaglandin biosynthesis, nitric oxide synthase (NOS) $1^{7}$ and production of cytokines such as IL-6, tumour necrosis factor $\alpha$ (TNF $\alpha$ ), IL-1, IL-22 and IL-33. ${ }^{2}$ Among patients with CRS requiring surgery, the bitter taste receptor T2R38 genotype was different from the general population. ${ }^{8}$ Recently, a replication study on genetic variants in CRS showed the highest consistency and significance for SNPs in TGFB1, NOS1 and PARS2 (an amino acid activator for protein synthesis). ${ }^{9}$

\section{Immune deficiencies}

Respiratory diseases have been linked to both primary and secondary immune deficiencies (PID/SID).

In Western countries, the most common PID is common variable immune deficiency (CVID), which is defined by a general impaired antibody production. Other humoral PIDs present as specific immunoglobulin (Ig) deficiencies. Among patients with CVID, 36-78\% have CRS in addition to 
Table 1 Summary of reported effect of endogenous and exogenous factors on either rhinitis or rhinosinusitis

\begin{tabular}{|c|c|c|}
\hline & Rhinitis & Rhinosinusitis \\
\hline \multicolumn{3}{|l|}{ Endogenous factors } \\
\hline Genetic factors & $\begin{array}{l}\text { Allergic rhinitis: SNPs in genes coding for leucotrienes, chemokines, } \\
\text { chemokine receptors, cytokines, TLRs }{ }^{5} \\
\text { Non-allergic rhinitis: SNPs in genes coding for Cfos and Cdc } 242^{6}\end{array}$ & $\begin{array}{l}\text { CRS with nasal polyps: SNPs in genes coding for TGF- } \beta 1 \text {, } \\
\text { iNOS, PARS2, IL-1 } \alpha, \text { IL-33, genes related to eosinophilia }{ }^{2}\end{array}$ \\
\hline Immune deficiencies & \multicolumn{2}{|c|}{$\begin{array}{l}\text { Primary humoral immune deficiencies: increased prevalence of chronic upper airway disease (specific, common variable and SPAD) }{ }^{2} \\
\text { Secondary immune deficiencies: difficult-to-treat rhinosinusitis with resistant or uncommon microorganisms }{ }^{12}\end{array}$} \\
\hline Hormones & $\begin{array}{l}\text { Pregnancy rhinitis }{ }^{18} \\
\text { Anecdotal reports linking rhinitis to hypothyroidism and acromegaly }{ }^{20}\end{array}$ & Anecdotal reports linking rhinosinusitis to hypothyroidism ${ }^{20}$ \\
\hline Systemic diseases & Sarcoidosis ${ }^{25}$ & $\begin{array}{l}\text { Difficult-to-treat CRS in Churg-Strauss syndrome } e^{24} \\
\text { Granulomatosis with polyangiitis }{ }^{22} \text { Sarcoidosis }^{25}\end{array}$ \\
\hline Psychological factors & $\begin{array}{l}\text { Increased prevalence of allergic rhinitis in persons who experienced } \\
\text { stressful life events }{ }^{26} 27 \\
\text { Increased risk of developing upper airway infection in subjects with } \\
\text { psychological stress }{ }^{31}\end{array}$ & \\
\hline \multicolumn{3}{|l|}{ Exogenous factors } \\
\hline Viruses & Common cold & $\mathrm{ARS}^{2}$ \\
\hline Bacteria & Staphylococcus aureus colonisation is increased in allergic rhinitis ${ }^{47}$ & $\begin{array}{l}\text { Superinfection of viral } \mathrm{ARS}^{70} \\
\text { CRS with nasal polyps: increased colonisation with S. aureus and } \\
\text { increased IgE towards } S \text {. aureus enterotoxins }{ }^{47}\end{array}$ \\
\hline Fungi & Can cause allergic sensitisation & $\begin{array}{l}\text { Mycetoma or fungal ball (one sinus) } \\
\text { AFRS (multiple sinuses) } \\
\text { Granulomatous and chronic invasive FRS in immunocompromised } \\
\text { patients }^{49}\end{array}$ \\
\hline Allergens & Cause of allergic rhinitis ${ }^{1}$ & Increased prevalence of CRS in atopic patients ${ }^{56}$ \\
\hline Occupational agents & $\begin{array}{l}\text { Allergic rhinitis to HMW allergens } \\
\text { Allergic rhinitis to LMW sensitisers } \\
\text { Irritant-induced rhinitis }\end{array}$ & Increased occupational exposure in FESS-requiring CRS patients ${ }^{56}$ \\
\hline Cigarette smoke & Active and passive smoking increase the risk of developing rhinitis ${ }^{61}$ & Higher prevalence of CRS in smokers ${ }^{62}$ \\
\hline Pollution and DEP & DEP aggravate pre-existing rhinitis ${ }^{68}$ & Weak association between pollution and prevalence of $\mathrm{CRS}^{69}$ \\
\hline
\end{tabular}

having frequent episodes of bronchitis and pneumonia. ${ }^{2}$ In a study involving 300 patients with refractory CRS, $21.8 \%$ showed a humoral immunodeficiency ${ }^{2}$ and, in a comparable study including 74 patients with rhinosinusitis, 19\% had low immunoglobulin levels, $31 \%$ had one or more $\operatorname{IgG}$ subclass deficiencies and $26 \%$ had low IgG3 levels. ${ }^{2}$ However, the relevance of these findings is unclear since specific IgG subclass deficiencies are frequent in the general population. In addition, immunoglobulin treatment hardly provides benefit to patients with CRS. ${ }^{2}$

A distinct group of patients with PID shows a specific polysaccharide antibody deficiency syndrome (SPAD) characterised by a poor serological response to polysaccharide antigens despite normal levels of immunoglobulins. Although contradictory guidelines hamper correct diagnosis, patients with SPAD present with recurrent upper airway infections and seem to have an increased risk of developing allergic rhinitis. ${ }^{10}$ Also, in patients with CRS requiring surgery, $11.6 \%$ were diagnosed with SPAD. ${ }^{11}$

Marked forms of cellular immune deficiencies such as defects in T cell function, cytokine or signalling defects are often associated with severe and atypical infections (with mycobacteria and fungi) of the upper airways. Information about deficiencies in the innate immune system is given in the online supplement.

In secondary immune deficiencies caused by HIV infection or chemotherapy and in transplant patients, upper airway disease is also a common complication. In HIV-positive patients a majority reported rhinitis (80\%) and rhinosinusitis (54\%). ${ }^{12}$ In addition, secondary immunodeficient patients are at risk of developing a difficult-to-treat rhinosinusitis with resistant or uncommon microorganisms and fungi.

\section{Mucociliary clearance dysfunction}

Cystic fibrosis (CF) and primary ciliary dyskinesia (PCD) are both characterised by congenital defects in the mucociliary transport system leading to serious chronic upper and lower airway problems.

In patients with PCD, rhinitis is a lifetime problem ${ }^{13}$ often from the first days of life onwards with impaired breast feeding due to nasal blockage. This should be an alarm sign to investigate ciliary dysfunction. Later in life, patients with PCD also suffer from CRS, generally in the absence of nasal polyps. ${ }^{14}$ When this occurs in conjunction with atypical asthma, bronchiectasis, chronic productive cough and severe otitis media, the presence of PCD should be suspected.

Among patients with CF, up to $97 \%$ have CRS, often with massive nasal polyps, ${ }^{15}$ and a correlation exists between the severity of upper and lower airway disease. ${ }^{16}$ Interestingly, heterozygous carriers of the CF mutation appear to have an increased incidence of CRS, suggesting that this mutation might be associated with the development of CRS in the general population. ${ }^{17}$

\section{Hormones}

Imbalances in the hormonal system such as pregnancy have been associated with the development of rhinitis and rhinosinusitis. Pregnancy rhinitis, which has a cumulative incidence of $22 \%,{ }^{18}$ typically starts during the second month of pregnancy and usually disappears rapidly after delivery. Neither atopy nor asthma seem to be risk factors. ${ }^{18}$ The pathogenesis remains largely unexplained, but a number of theories have been proposed. Oestrogens cause vasodilation by increasing nitric oxide 
production, ${ }^{19}$ have a proinflammatory effect (chemotaxis and maturation of mast cells) ${ }^{\mathrm{E} 34}$ and increase the expression of histamine receptors on nasal epithelial and endothelial cells. ${ }^{\text {E35 }}$ Whether pregnancy rhinitis predisposes to rhinosinusitis is not clear, but two small studies indicate that the incidence of rhinosinusitis is not increased in pregnant women.

Although rhinitis as well as CRS have been described to occur with thyroid disease, evidence linking hypothyroidism directly with (sino)nasal pathology is limited. ${ }^{20}$

It has also been proposed that rhinitis occurs in acromegaly, however nasal congestion does not occur in response to low-dose recombinant growth hormone. ${ }^{20}$

\section{Vasculitis and granulomatous disease}

Systemic autoimmune diseases such as systemic lupus erythematosus, relapsing polychondritis and Sjögren syndrome may present with difficult-to-treat rhinosinusitis in addition to pulmonary problems. The most prevalent systemic diseases with upper airway involvement are Churg-Strauss syndrome (CSS) and granulomatosis with polyangiitis (GPA; previously Wegener's granulomatosis). Here, chronic rhinitis and recalcitrant rhinosinusitis are often initial manifestations before lower airway and systemic symptoms arise.

Over $75 \%$ of patients with GPA and CSS present with upper respiratory tract symptoms, usually nasal obstruction and chronic recurrent infections. ${ }^{21}$ In a study from 2009, 61\% of patients with GPA had CRS, ${ }^{22}$ commonly manifested as bloody discharge, crusting and nasal obstruction. ${ }^{23}$ In CSS, asthma is preceded by upper airway symptoms such as rhinitis or CRS with or without nasal polyps in about $75 \%$ of cases. ${ }^{24}$ Compared with lesions seen in GPA, the nasal and sinus lesions of patients with CSS are typically non-erosive, although crusting and epistaxis can occur.

Sarcoidosis is a multiorgan disease with pulmonary involvement in $>90 \%$ of cases. Although $<5 \%$ of patients develop sarcoid of the nose and sinuses, at the time of presentation these patients are almost always symptomatic with nasal obstruction, rhinorrhoea or crusting. ${ }^{25}$

\section{Psychological stress}

It is well known that psychological stress can alter the immune homeostasis. The deteriorating role of psychological stress on asthma has been documented, but little is known on the relationship with upper airway disease. A large-scale Finnish study showed that severe emotional stress increased the risk of allergic rhinoconjunctivitis. ${ }^{26}$ Perceived stress was even associated with atopic disorders in a dose-dependent manner, with a significantly increased prevalence of new onset rhinitis in adults who experienced more stressful events. ${ }^{27}$ Stressful events during pregnancy were also associated with an increased prevalence of rhinitis in the mother's offspring, ${ }^{28}$ as has been previously shown for asthma. Additionally, children with caregivers who experienced higher stress levels showed higher total serum IgE, a greater peripheral leucocytic allergen-specific response, as well as increased $\mathrm{TNF} \alpha$ and decreased interferon $\gamma$ (IFN $\gamma$ ) production. ${ }^{29}$ In addition to stress, anxiety (but not depression) also seems to be associated with both rhinitis and asthma. ${ }^{30}$ Whether stressful events increase the risk of developing airway problems or whether airway disease predisposes to stress and anxiety still remains to be elucidated.

Additionally, psychological stress has been shown to affect susceptibility to viral rhinitis. A large prospective study showed that the level of psychological stress was associated in a dose-dependent way with the risk of developing acute upper airway infection assessed by virus isolation in nasal lavage or antibody titres. ${ }^{31}$
The direct influence of stress on airway inflammation has only been investigated in the lower airways. One of these studies showed a lower expression of glucocorticoid receptors on peripheral leucocytes of children who experienced stress. ${ }^{\text {E36 }}$ Another study suggested activation of airway mast cells by corticotropin releasing hormone, a hormone that is secreted in the airways under stress conditions. ${ }^{\text {E37 }}$

Although it is likely that psychological state and stress can influence the development and maintenance of rhinosinusitis, to our knowledge there are no published data discussing this relationship.

\section{EXOGENOUS FACTORS ASSOCIATED WITH UPPER AIRWAY INFLAMMATION}

\section{Viruses in upper airway disease}

Viruses are the major cause of acute infectious rhinitis and approximately $50 \%$ of common colds are caused by human rhinoviruses (HRV). ${ }^{32}$ However, it is hard to distinguish a viral infection from viral-induced exacerbations of chronic airway disease, even at the molecular level.

Allergic patients seem to clear viral infections less effectively than healthy individuals, which is in agreement with the in vitro observation of an attenuated inflammatory response of airway epithelial cells to HRV after house dust mite exposure. ${ }^{33}$ However, the functional relevance still remains unclear since allergy does not necessarily alter symptomatology or inflammation during a common cold ${ }^{34}$ (see additional information in online supplement).

The relationship between viral rhinitis and exacerbations of asthma or COPD has been recognised for years. ${ }^{35}$ Although asthmatic patients and those with COPD do not have more viral upper airway infections, they seem to have more severe and persistent symptoms in both upper and lower airways. The majority of asthma exacerbations follow viral upper respiratory tract infections, more than $50 \%$ of which are caused by $\mathrm{HRV}^{36}$ and HRV infection directly affects lung function in people with asthma. ${ }^{37}$ Upper airway viruses are also detected in $22-57 \%$ of COPD exacerbations. ${ }^{35}$ These findings have been attributed to an aberrant IFN response to viral infection, and hence insufficient clearance of HRV in patients with atopic asthma ${ }^{38}$ and COPD ${ }^{39}$ although this remains debated.

Despite the frequency of viral rhinitis, the role of viral infections in CRS has not been well studied. Viruses may contribute to CRS exacerbations and also to the pathogenesis of CRS. Although patients often report that a cold preceded the development of CRS, robust data supporting this hypothesis are lacking. Mechanistically, viruses could contribution to CRS via polyclonal IgE activation, ${ }^{40}$ induction of local immune responses ${ }^{41}$ and facilitation of bacterial penetration through the epithelial barrier. ${ }^{42}$ However, other data suggest that viral infections and antiviral responses do not differ between patients with CRS and healthy individuals. ${ }^{43}$

\section{Bacteria}

It is estimated that $0.5-2 \%$ of viral upper respiratory tract infections are complicated by bacterial infection. In acute sinusitis, cultures of sinus secretions obtained by sinus puncture predominantly grow Streptococcus pneumoniae, Haemophilus influenzae and Moraxella catarrhalis.

The contribution of bacterial infection to CRS remains unclear. Polymicrobial specimens have been isolated from both diseased and non-diseased sinuses in patients with CRS, suggesting that bacterial presence by itself is not the most significant cause of CRS. ${ }^{44}$ Microbiome studies have confirmed that the sinuses of healthy people are inhabited by a rich and diverse 
community of bacteria. ${ }^{45}$ However, the sinonasal microbiome from patients with CRS may exhibit less diversity and the bacterial load might be different from healthy control subjects. ${ }^{45} 46$ Interestingly, invasive bacterial infections are typically characterised by strong neutrophil-mediated inflammation whereas inflammation observed in the majority of Caucasian patients with CRS is eosinophilic (see additional information in online supplement).

Recently, the role of biofilms and superantigens in CRS has been intensively investigated. Bacteria are believed to use biofilms to chronically infect sinuses without tissue invasion; however, their role in disease pathogenesis remains controversial. Superantigens represent a growing family of bacterial and viral proteins that can induce massive immune activation, with Staphylococcus aureus enterotoxins (SAE) receiving the greatest attention. Patients with allergic rhinitis carry more $S$. aureus than control subjects, ${ }^{47}$ but the most important findings were seen in CRS: patients with CRS with nasal polyps were more frequently colonised with $S$. aureus than control individuals and patients with CRS without nasal polyps. ${ }^{47}$ IgE antibodies to SAE (SE-IgE) were significantly higher in patients with nasal polyps-especially in those with concomitant asthma-than control individuals and patients with CRS without nasal polyps. Additionally, the presence of SE-IgE was associated with an increased risk of developing comorbid asthma in patients with CRS with nasal polyps ${ }^{47}$ and, in a recent study involving almost 3000 European subjects, nasal SE-IgE levels were associated with asthma in a concentration-dependent manner. ${ }^{48}$ These findings suggest a role for SAE as upper airway disease modifiers, specifically in CRS with nasal polyps and, possibly, as a player in determining nasobronchial interactions.

Regarding the use of antibiotics for CRS treatment, only one randomised placebo-controlled trial using a macrolide antibiotic for several months showed efficacy. ${ }^{2}$ A similarly designed study showed no improvement in the macrolide therapy arm compared with placebo, ${ }^{2}$ although a retrospective study demonstrated a beneficial effect in recalcitrant CRS. ${ }^{2}$ Moreover, a randomised placebo-controlled study showed a moderate beneficial effect of doxycycline in patients with CRS with nasal polyps. ${ }^{2}$

\section{Fungi}

Fungi can cause a variety of adverse health effects by both immunological and non-immunological mechanisms. Immunologically, moulds produce allergens that lead to allergic rhinitis in an estimated $3-20 \%$ of the world's population. Non-immunological effects of fungi include infection, irritation of mucous membranes and reactions to mycotoxins. ${ }^{49}$

Fungal disorders affecting the sinuses are classified into invasive and non-invasive diseases. The invasive diseases include acute or chronic invasive fungal rhinosinusitis (FRS) and granulomatous invasive FRS and they generally occur in immunocompromised hosts only. Non-invasive forms of FRS include sinus mycetoma (fungal ball), in general affecting only one sinus, and allergic FRS (AFRS), affecting multiple sinuses. AFRS is accepted as an immunologically distinct form of CRS and has several similarities with allergic bronchopulmonary aspergillosis (ABPA). Both are chronic inflammatory respiratory tract disorders driven by type I and III hypersensitivity towards fungi growing within eosinophilic mucin present in the paranasal sinuses or bronchi. Patients with AFRS typically have unilateral CRS symptoms, often with dark thick mucoid secretions. ${ }^{50}$ The histopathology of ABPA and AFRS is very similar, ${ }^{50}$ but the immunology of AFRS has been less extensively studied and the existence of AFRS without detectable fungal hyphae in sinuses or fungal sensitisation is troublesome. ${ }^{51}$ Although ABPA and AFRS may coexist, epidemiological data are insufficient to state that they are presentations of a common allergic fungal airway disease.

For many years an IgE-mediated systemic fungal allergy has been thought to drive the pathological process characteristic of most forms of CRS. However, the finding that topical or systemic antifungal agents are not beneficial in patients with CRS pleads against this hypothesis. ${ }^{49}$ Nevertheless, a diseasemodifying role for fungi cannot be completely excluded.

\section{Allergens}

One of the best known causes of chronic rhinitis is allergy, affecting about 400 million people worldwide. ${ }^{1}$ The sequence of events involving activation of Th2 cells and production of antigen-specific IgE leading to allergic rhinitis is well known and described in more depth in the online supplement.

In addition to the well-characterised activation of the adaptive immune system, several allergens (eg, Der $p 1$ and 9 in house dust mite) have proteolytic activity with the capacity of disrupting tight junctions, leading to disintegration of the epithelial barrier. ${ }^{52}$ Some allergens can also activate epithelial cells directly, triggering an influx of innate immune cells and promoting Th2-polarised adaptive immune responses. ${ }^{53}$ Possible mechanisms include direct co-activation of TLRs by allergenic proteins such as $\operatorname{Der} p 2^{54}$ or increased epithelial production of IL-25, a potentiator of the Th2 response, upon exposure to allergen proteases. ${ }^{55}$

Allergic rhinitis is relatively easy to diagnose based on the combination of typical symptoms and positive skin prick tests (SPT) or antigen-specific IgEs in the serum. It has been suggested that some patients with negative SPT or serum IgEs against the suspected allergens may suffer from a 'locally mediated allergic rhinitis'. This is elaborated on in the online supplement.

Multiple studies have shown a higher prevalence of positive SPT in patients with CRS (50-80\%) compared with the general population, ${ }^{56}$ although this does not prove causality.

The link between allergic rhinitis and asthma has been studied extensively. Up to $90 \%$ of patients with asthma have allergic rhinitis and one-third of patients with allergic rhinitis have asthma. ${ }^{57}$ Besides being linked anatomically, the nose and bronchi also communicate via indirect mechanisms such as neural and systemic pathways that are believed to be responsible for the nasobronchial interaction. ${ }^{58}$

\section{Occupational agents}

Many agents inhaled at work can harm the airways. Occupational rhinitis has been estimated to occur 2-4 times more often than occupational asthma and it generally precedes its development.

Inhaled occupational agents are classified into high molecular weight (HMW) and low molecular weight (LMW) compounds. ${ }^{59} \mathrm{HMW}$ agents are biological (glyco)proteins present in, for example, flour, mites, laboratory animals or latex, which can cause an allergic airway inflammation via the same mechanisms as described above for non-occupational aeroallergens. Some LMW chemicals can induce immune sensitisation by acting as haptens and, after an asymptomatic latency phase, they may cause airway symptoms upon repeated contact. A second group of LMW agents consists of irritants, and acute accidental exposure to high irritant concentrations causes injury to the respiratory mucosa which may lead to persistent respiratory symptoms. ${ }^{59}$ As with irritant-induced asthma, evidence is now growing that repeated or long-term exposures to lower concentrations of irritants might also induce chronic dysfunction of the nasal mucosa. For example, cleaners, swimming pool workers 
and competitive swimmers who are all chronically exposed to chlorination products suffer more from asthma and also from upper airway symptoms than controls. Similar findings have been reported in beverage processing plant workers chronically exposed to low levels of hydrogen peroxide ${ }^{59}$ (see additional information in online supplement).

A recently proposed concept is that of 'occupational rhinosinusitis'. This was based on a large-scale retrospective assessment of occupational exposures in patients with rhinosinusitis requiring surgery which showed a higher prevalence of 'dirty jobs' among the patients with rhinosinusitis patients than controls. ${ }^{56}$ Exposures that were most frequently mentioned in the study were chlorination products, inorganic dust, paints, cement, thinner, ammonia, white spirit and acetone. Interestingly, irritants were more frequently involved than sensitisers. This finding was supported by a Finnish study showing lower surgical satisfaction in patients reporting occupational exposures. ${ }^{60}$

\section{Smoking}

The impact of tobacco smoke has been less well studied on the upper airways than on the lungs. Nevertheless, several studies have shown that active as well as passive smoking increases the risk of developing chronic rhinitis and rhinosinutis. ${ }^{61} \mathrm{~A}$ multicentre pan-European survey recently confirmed the strong association between smoking and $\mathrm{CRS}^{62}$ with a dose-dependent relationship with pack-years of smoking. A Polish prospective study investigating 279 patients with CRS undergoing sinus surgery showed that revision surgery was significantly more frequent in smokers than non-smokers. ${ }^{63}$

In smokers, nasal and bronchial inflammation, characterised by infiltration of CD8 + lymphocytes, often coexist. However, different cytokine responses occur upon exposure of human nasal and bronchial epithelial cells to cigarette smoke extract. ${ }^{64}$ The smoke components formaldehyde and acrolein act as local irritants on the upper airways and nicotine can influence physiological processes as well as cell transport systems of the nasal epithelium. ${ }^{65}$ Cigarette smoke may aggravate pre-existing allergic rhinitis, as shown by an increased number of eosinophils in the nasal mucosa of patients with allergic rhinitis exposed to smoke compared with non-exposed patients. ${ }^{66}$

\section{Ambient air pollution}

Ambient air pollution consists of a mixture of gases (including sulphur dioxide and nitrogen dioxide) and particulate matter (PM) which is characterised according to size (eg, $\mathrm{PM}_{10}$ or $\mathrm{PM}_{2.5}$ for particles $<10 \mu \mathrm{m}$ or $<2.5 \mu \mathrm{m}$, respectively). In industrially developed countries, diesel engines are a major source of air pollution. Duhme et al $^{67}$ demonstrated that adolescents living on streets with constant truck traffic were $71 \%$ more likely to report symptoms of rhinitis.

A direct causal role for diesel exhaust particles (DEP) in the induction of rhinitis has not yet been demonstrated, but DEP affects the nasal environment in many ways. In nasal provocation experiments it was shown that DEP enhances the expression of several cytokines (IL-2, IL-4, IL-5 IL-6, IL-13 and IFN $\gamma$ ), chemokines (RANTES, macrophage inflammatory protein-1 $\alpha$, monocyte chemotactic protein-3, but not eotaxin) as well as IgE levels in nasal lavage and numbers of IgE-secreting B cells in the nasal mucosa. ${ }^{68}$ Nasal exposure of atopic subjects to DEP potentiated primary sensitisation towards a neo-allergen, suggesting that DEP can act as a mucosal adjuvant. Chronic exposure to diesel exhaust can also induce nasal epithelial changes with goblet cell hyperplasia and increased metaplastic and dysplastic epithelial cells. ${ }^{68}$
Exposure to DEP can also aggravate pre-existing allergic rhinitis, as shown for allergic asthma. Nasal challenge of patients with allergic rhinitis with a relevant allergen with or without DEP showed that DEP aggravated local histamine release and clinical symptoms and that lower allergen doses were required to trigger symptoms. ${ }^{68}$ Combined exposure to ragweed and DEP also resulted in a strong induction of ragweed-specific IgE and $\mathrm{IgG}_{4}$ in nasal lavage compared with ragweed alone. ${ }^{68}$

In vitro studies on human nasal epithelial cells demonstrated that DEP are phagocytised leading to the production of IL-8, granulocyte-macrophage colony-stimulating factor (GM-CSF) and IL-1 $\beta$ and induction of oxidative stress. ${ }^{68}$ Additionally, DEP can upregulate histamine receptor mRNA and increase histamine-induced IL- 8 and GM-CSF production in nasal epithelial and endothelial cells. ${ }^{68}$

Data on pollution and CRS are scarce. However, one German study demonstrated a weak but significant effect of raised urban air pollution levels on the prevalence of CRS. ${ }^{69}$

\section{CONCLUSION}

Chronic upper airway disease is one of the most important chronic disease entities in the Western world. Although current diagnostics in chronic upper airway disease mainly focus on infection and the detection of atopy, several other endogenous as well as exogenous factors can play a role in the development of the disease. Table 1 lists these factors and summarises their possible effects on upper airway function. Because of the wellknown link between upper and lower airway disease and their reciprocal interference, we believe that knowledge of these factors is indispensable for the practising pulmonologist in order to fully evaluate a chronic airway problem. Awareness of these factors in patients with airway symptoms can result in a more individually-directed therapy and may represent a major step forward in the diagnostic and therapeutic approach in patients with chronic airway disease.

Contributors VH: conception, design, writing, revising. TM, WH, CVD, JAV, GJ, WF, CB and JLC: writing, revising, approval. BN: conception, design, writing, revising, approval. PWH: conception, design, writing, revising, approval.

Funding The project was supported by a grant from the Interuniversitary Attraction Pole Program, Belgian State, Belgian Science Policy P7/30 and from the Research Foundation Flanders (FWO). VH is a research fellow of the FWO, JAV is a post-doctoral research fellow of FWO and PWH is a recipient of a senior researcher fellowship from FWO. CB is a recipient of a senior researcher fellowship from FWO.

Competing interests None.

Provenance and peer review Not commissioned; externally peer reviewed.

\section{REFERENCES}

1 Bousquet J, Khaltaev N, Cruz AA, et al. Allergic Rhinitis and its Impact on Asthma (ARIA) 2008 update (in collaboration with the World Health Organization, GA(2) LEN and AllerGen). Allergy 2008;63(Suppl 86):8-160.

2 Fokkens WJ, Lund VJ, Mullol J, et al. EPOS 2012: European position paper on rhinosinusitis and nasal polyps 2012. A summary for otorhinolaryngologists. Rhinology 2012;50:1-12.

3 Kim WK, Kwon JW, Seo JH, et al. Interaction between IL13 genotype and environmental factors in the risk for allergic rhinitis in Korean children. J Allergy Clin Immunol 2012;130:421-6.

4 Frischmeyer-Guerrerio PA, Guerrerio AL, Oswald G, et al. TGFbeta receptor mutations impose a strong predisposition for human allergic disease. Sci Trans/ Med 2013;5:195ra94.

5 Nilsson D, Andiappan AK, Hallden C, et al. Toll-like receptor gene polymorphisms are associated with allergic rhinitis: a case control study. BMC Med Genet 2012;13:66.

6 Cardell LO, Andersson M, Cervin A, et al. Genes regulating molecular and cellular functions in noninfectious nonallergic rhinitis. Allergy 2009;64:1301-8.

7 Benito Pescador D, Isidoro-Garcia M, Garcia-Solaesa V, et al. Genetic association study in nasal polyposis. J Investig Allergol Clin Immunol 2012;22:331-40. 
8 Adappa ND, Zhang Z, Palmer JN, et al. The bitter taste receptor T2R38 is an independent risk factor for chronic rhinosinusitis requiring sinus surgery. Int Forum Allergy Rhinol 2014;4:3-7

9 Henmyr V, Vandeplas G, Hallden C, et al. Replication study of genetic variants associated with chronic rhinosinusitis and nasal polyposis. J Allergy Clin Immunol 2014;133:273-5.

10 Cheng YK, Decker PA, O'Byrne MM, et al. Clinical and laboratory characteristics of 75 patients with specific polysaccharide antibody deficiency syndrome. Ann Allergy Asthma Immunol 2006;97:306-11.

11 Carr TF, Koterba AP, Chandra R, et al. Characterization of specific antibody deficiency in adults with medically refractory chronic rhinosinusitis. Am J Rhino Allergy 2011;25:241-4.

12 Porter JP, Patel AA, Dewey CM, et al. Prevalence of sinonasal symptoms in patients with HIV infection. Am J Rhinol 1999;13:203-8.

13 Boon $M$, Jorissen $M$, Proesmans $M$, et al. Primary ciliary dyskinesia, an orphan disease. Eur J Pediatr 2013;172:151-62.

14 Rollin M, Seymour K, Hariri M, et al. Rhinosinusitis, symptomatology \& absence of polyposis in children with primary ciliary dyskinesia. Rhinology 2009;47:75-8.

15 Kerrebijn JD, Poublon RM, Overbeek SE. Nasal and paranasal disease in adult cystic fibrosis patients. Eur Respir J 1992;5:1239-42.

16 Roby BB, McNamara J, Finkelstein M, et al. Sinus surgery in cystic fibrosis patients: comparison of sinus and lower airway cultures. Int J Pediatr Otorhinolaryngol 2008;72:1365-9.

17 Wang X, Moylan B, Leopold DA, et al. Mutation in the gene responsible for cystic fibrosis and predisposition to chronic rhinosinusitis in the general population. JAMA 2000;284:1814-19.

18 Ellegard E, Hellgren M, Toren K, et al. The incidence of pregnancy rhinitis. Gynecol Obstet Invest 2000;49:98-101.

19 Yang S, Bae L, Zhang L. Estrogen increases eNOS and NOx release in human coronary artery endothelium. J Cardiovasc Pharmacol 2000;36:242-7.

20 van Rijswijk JB, Blom HM, Fokkens WJ. Idiopathic rhinitis, the ongoing quest. Allergy 2005;60:1471-81.

21 Martinez Del PM, Sivasothy P. Vasculitis of the upper and lower airway. Best Pract Res Clin Rheumatol 2009;23:403-17.

22 Cannady SB, Batra PS, Koening C, et al. Sinonasal Wegener granulomatosis: a single-institution experience with 120 cases. Laryngoscope 2009;119:757-61.

23 Sproson EL, Jones NS, Al-Deiri M, et al. Lessons learnt in the management of Wegener's granulomatosis: long-term follow-up of 60 patients. Rhinology 2007:45:63-7.

24 Bacciu A, Bacciu S, Mercante G, et al. Ear, nose and throat manifestations of Churg-Strauss syndrome. Acta Otolaryngol 2006;126:503-9.

25 Zeitlin JF, Tami TA, Baughman R, et al. Nasal and sinus manifestations of sarcoidosis. Am J Rhinol 2000;14:157-61.

26 Kilpelainen $M$, Koskenvuo M, Helenius $H$, et al. Stressful life events promote the manifestation of asthma and atopic diseases. Clin Exp Allergy 2002; 32:256-63.

27 Rod NH, Kristensen TS, Lange $\mathrm{P}$, et al. Perceived stress and risk of adult-onset asthma and other atopic disorders: a longitudinal cohort study. Allergy 2012;67:1408-14.

28 de Marco R, Pesce G, Girardi P, et al. Foetal exposure to maternal stressful events increases the risk of having asthma and atopic diseases in childhood. PediatrAllergy Immunol 2012;23:724-9.

29 Wright RJ, Finn P, Contreras JP, et al. Chronic caregiver stress and IgE expression, allergen-induced proliferation, and cytokine profiles in a birth cohort predisposed to atopy. J Allergy Clin Immunol 2004;113:1051-7.

30 Slattery MJ, Essex MJ. Specificity in the association of anxiety, depression, and atopic disorders in a community sample of adolescents. J Psychiatr Res 2011;45:788-95.

31 Cohen S, Tyrrell DA, Smith AP. Psychological stress and susceptibility to the common cold. N Engl J Med 1991;325:606-12.

32 Makela MJ, Puhakka T, Ruuskanen 0, et al. Viruses and bacteria in the etiology of the common cold. J Clin Microbiol 1998;36:539-42.

33 Bossios A, Gourgiotis D, Skevaki CL, et al. Rhinovirus infection and house dust mite exposure synergize in inducing bronchial epithelial cell interleukin-8 release. Clin Exp Allergy 2008;38:1615-26.

34 Skoner DP, Doyle WJ, Seroky J, et al. Lower airway responses to rhinovirus 39 in healthy allergic and nonallergic subjects. Eur Respir J 1996;9:1402-6.

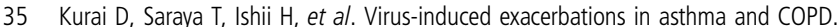
Front Microbiol 2013;4:293.

36 Johnston SL, Pattemore PK, Sanderson G, et al. Community study of role of viral infections in exacerbations of asthma in 9-11 year old children. BMJ 1995:310:1225-9.

37 Cheung D, Dick EC, Timmers MC, et al. Rhinovirus inhalation causes long-lasting excessive airway narrowing in response to methacholine in asthmatic subjects in vivo. Am J Respir Crit Care Med 1995;152(5 Pt 1):1490-6.

38 Wark PA, Johnston SL, Bucchieri F, et al. Asthmatic bronchial epithelial cells have a deficient innate immune response to infection with rhinovirus. J Exp Med 2005;201:937-47.
39 Mallia P, Message SD, Gielen V, et al. Experimental rhinovirus infection as a human model of chronic obstructive pulmonary disease exacerbation. Am J Respir Crit Care Med 2011;183:734-42.

40 Becker Y. Respiratory syncytial virus (RSV) evades the human adaptive immune system by skewing the Th1/Th2 cytokine balance toward increased levels of Th2 cytokines and IgE, markers of allergy: a review. Virus Genes 2006;33:235-52.

41 Yamin M, Holbrook EH, Gray ST, et al. Cigarette smoke combined with Toll-like receptor 3 signaling triggers exaggerated epithelial regulated upon activation, normal T-cell expressed and secreted/CCL5 expression in chronic rhinosinusitis. J Allergy Clin Immunol 2008;122:1145-53 e3.

42 Wang $X$, Zhang N, Glorieux S, et al. Herpes simplex virus type 1 infection facilitates invasion of Staphylococcus aureus into the nasal mucosa and nasal polyp tissue. PLoS One 2012;7:e39875.

43 Wang JH, Kwon HJ, Chung YS, et al. Infection rate and virus-induced cytokine secretion in experimental rhinovirus infection in mucosal organ culture: comparison between specimens from patients with chronic rhinosinusitis with nasal polyps and those from normal subjects. Arch Otolaryngol Head Neck Surg 2008;134:424-7.

44 Bhattacharyya N. Bacterial infection in chronic rhinosinusitis: a controlled paired analysis. Am J Rhinol 2005;19:544-8.

45 Boase $S$, Foreman $A$, Cleland $E$, et al. The microbiome of chronic rhinosinusitis: culture, molecular diagnostics and biofilm detection. BMC Infect Dis 2013;13:210.

46 Abreu NA, Nagalingam NA, Song Y, et al. Sinus microbiome diversity depletion and Corynebacterium tuberculostearicum enrichment mediates rhinosinusitis. Sci Trans/ Med 2012:4:151ra24.

47 Huvenne W, Hellings PW, Bachert C. Role of staphylococcal superantigens in airway disease. Int Arch Allergy Immunol 2013;161:304-14.

48 Tomassen $\mathrm{P}$, Jarvis D, Newson $\mathrm{R}$, et al. Staphylococcus aureus enterotoxin-specific $\mathrm{IgE}$ is associated with asthma in the general population: a GA(2)LEN study. Allergy 2013;68:1289-97.

49 Fokkens WJ, Ebbens F, van Drunen CM. Fungus: a role in pathophysiology of chronic rhinosinusitis, disease modifier, a treatment target, or no role at all? Immunol Allergy Clin North Am 2009;29:677-88.

50 Ryan MW. Allergic fungal rhinosinusitis. Otolaryngol Clin North Am 2011;:44:697-710, ix-x.

51 Allphin AL, Strauss M, Abdul-Karim FW. Allergic fungal sinusitis: problems in diagnosis and treatment. Laryngoscope 1991;101:815-20.

52 Hammad H, Lambrecht BN. Dendritic cells and epithelial cells: linking innate and adaptive immunity in asthma. Nat Rev Immunol 2008;8:193-204.

53 Wills-Karp M, Nathan A, Page K, et al. New insights into innate immune mechanisms underlying allergenicity. Mucosal Immunol 2010;3:104-10.

54 Trompette A, Divanovic $\mathrm{S}$, Visintin A, et al. Allergenicity resulting from functional mimicry of a Toll-like receptor complex protein. Nature 2009;457:585-8.

55 Kouzaki H, Tojima I, Kita H, et al. Transcription of interleukin-25 and extracellular release of the protein is regulated by allergen proteases in airway epithelial cells. Am J Respir Cell Mol Biol 2013;49:741-50.

56 Hox V, Delrue S, Scheers $H$, et al. Negative impact of occupational exposure on surgical outcome in patients with rhinosinusitis. Allergy 2012;67:560-5.

57 Shaaban R, Zureik M, Soussan D, et al. Rhinitis and onset of asthma: a longitudinal population-based study. Lancet 2008;372:1049-57.

58 Hens G, Hellings PW. The nose: gatekeeper and trigger of bronchial disease. Rhinology 2006;44:179-87.

59 Hox V, Steelant B, Fokkens W, et al. Occupational upper airway disease: how work affects the nose. Allergy 2014;69:282-91.

60 Myller JP, Luukkainen AT, Huhtala HS, et al. Satisfaction with maxillary sinus surgery might be influenced by risk factors. Allergy Rhinol 2013;4:e6-e12.

61 Eriksson J, Ekerljung L, Sundblad BM, et al. Cigarette smoking is associated with high prevalence of chronic rhinitis and low prevalence of allergic rhinitis in men. Allergy 2013;68:347-54.

62 Hastan D, Fokkens WJ, Bachert $C$, et al. Chronic rhinosinusitis in Europe--an underestimated disease. A GA(2)LEN study. Allergy 2011;66:1216-23.

63 Krzeski A, Galewicz A, Chmielewski R, et al. Influence of cigarette smoking on endoscopic sinus surgery long-term outcomes. Rhinology 2011;49:577-82.

64 Comer DM, Elborn JS, Ennis M. Comparison of nasal and bronchial epithelial cells obtained from patients with COPD. PLOS ONE 2012;7:e32924.

65 Blank U, Ruckes C, Clauss W, et al. Effects of nicotine on human nasal epithelium: evidence for nicotinic receptors in non-excitable cells. Pflugers Arch 1997:434:581-6.

66 Montano-Velazquez BB, Garcia Vazquez FJ, Navarrete RC, et al. Influence of exposure to tobacco cigarette smoke on the eosinophil count in the nasal mucosa of young patients with perennial allergic rhinitis. Rhinology 2013;51:253-8.

67 Duhme $\mathrm{H}$, Weiland SK, Keil U, et al. The association between self-reported symptoms of asthma and allergic rhinitis and self-reported traffic density on street of residence in adolescents. Epidemiology 1996;7:578-82.

68 Riedl M, Diaz-Sanchez D. Biology of diesel exhaust effects on respiratory function. J Allergy Clin Immunol 2005;115:221-8; quiz 9.

69 Wolf C. Urban air pollution and health: an ecological study of chronic rhinosinusitis in Cologne, Germany. Health Place 2002;8:129-39.

70 Wald ER, Milmoe GJ, Bowen A, et al. Acute maxillary sinusitis in children. N Engl J Med 1981;304:749-54. 